Trivent Publishing

(C) The Authors, 2015

Available online at http://trivent-publishing.eu/

Philosophy, Communication, Media sciences Series

Volume Saint Gerard of Cenad: Tradition and Innovation

\title{
L'Église et l'État en Hongrie dans la première moitié du XIe siècle, avec un regard spécial sur Legenda Sancti Gerardi et Deliberatio
}

\author{
Remus Mihai Feraru \\ Départament d'Études Roumaines, Université de L'Ouest, \\ Timisoara, Roumanie, remusferaru@yahoo.fr
}

\begin{abstract}
Résumé
Notre étude porte sur les relations entre l'Église et l'État en Hongrie, dans la première moitié du XI siècle et leur implications sur le plan politique, idéologique et religieux. La relation étroite entre l'Église et la royauté hongroise caractérisait l'organisation politique de la Hongrie mediévale. Notre recherche se fonde particulièrement sur la biographie anonyme de l'évêque Gérard de Csanád (Legenda Sancti Gerardi) et Deliberatio, une traité théologique et philosophique appartenant au même Gérard; ces deux sources reflétent les rapports entre l'Église et l'État pendant les règnes des Étienne $I^{\text {er }}(997-1038)$ et ses successeurs Pierre Orseolo $(1038-1041$; 1044-1046) et Aba Sámuel (1041-1044).
\end{abstract}

Mots clés: Église; État; christianisation; politique religieuse; Hongrie médiévale; Saint Gérard de Csanád; Étienne I ${ }^{\text {er }}$ Legenda Sancti Gerardi; Deliberatio.

This is an Open Access article distributed in accordance with the Creative Commons Attribution Non Commercial (CC-BYNC-ND 4.0) license, which permits others to copy or share the article, provided original work is properly cited and that this is not done for commercial purposes. Users may not remix, transform, or build upon the material and may not distribute the modified material (http://creativecommons.org/licenses/by-nc/4.0/) DOI: 10.22618/TP.PCMS.20151.176004 


\section{Introduction}

L'installation des tribus magyares dans la Pannonie, vers $896^{1}$ et leur organisation sous la forme d'un royaume médiéval puissant ont eu des conséquences capitales sur le rapport des forces de cette partie de l'Europe. À la fin du $\mathrm{X}^{\mathrm{e}}$ siècle, le jeune État magyar se trouvait dans une zone d'interférence des deux grands pouvoirs de l'époque, l'Empire romain germanique à l'ouest et l'Empire byzantin, à l'est. Sur le plan interne, le grand-prince Géza (972-997) jeta les bases de l'État médiéval hongrois, consolidant le pouvoir central. Dans les deux dernières décennies du $\mathrm{X}^{\mathrm{e}}$ siècle, le jeune État magyar est devenu une mise importante dans la dispute entre le Saint-Empire romain germanique et Byzance qui voulaient l'attirer dans leur sphère d'influence. Le roi Étienne $\mathrm{I}^{\mathrm{er}}$ (997-1038) paracheva l'œuvre politique et de christianisation des Hongrois initiée par son prédécesseur, Géza. L'extension du christianisme en Hongrie a été possible grâce à l'activité des missionnaires latins, parmi lesquels on compte le moine bénédictin Gérard, le futur évêque de Csanád (1030-1046), qui fut une personnalité éminente de l'époque.

Le biographie anonyme de Saint Gérard (Legenda Sancti Gerardi) ${ }^{2}$ et Deliberatio ${ }^{3}$ - un traité théologique et philosophique - dont l'auteur est l'évêque de Csanád lui-même reflètent les relations entre la royauté magyare et l'Église pendant les règnes d'Étienne $\mathrm{I}^{\text {er }}$ et de ses successeurs Pierre Orseolo (1038-1041; 1044-1046) et Aba Sámuel (1041-1044); en même temps, les deux sources nous fournissent des renseignements précieuses sur l'activité d'évangélisation initiée par Saint Gérard dans l'évêché de Csanád, ainsi que sur la relation entre l'évêque et les trois rois magyars.

C'est bien sur la valorisation des informations fournies par Vita Sancti Gerardi et Deliberatio (sans ignorer d'autres sources aussi, qui concernent la même époque) que notre étude se propose d'aborder la problématique des relations entre l'Église et l'État en Hongrie, pendant la première moitié du $\mathrm{XI}^{\mathrm{e}}$

\footnotetext{
${ }^{1}$ Ioan-Aurel Pop, Românii și maghiarii în secolele IX-XIV. Geneza statului medieval în Transilvania, (ClujNapoca: Centrul de Studii Transilvane, 1996), 61-62. D’après une lettre de Theotmar, archevêque de Salzburg, adressée au pape en 900, la Pannonie était dévastée par les incursions des Magyars et des Moraves des années précédentes si bien que, à ce moment-là, dans toute la Pannonie il n'y avait plus aucune église, (« ... in tota Pannonia, nostra maxima provincia, tantum una non apparet ecclesia »), György Györffy, « La christianisation de la Hongrie ", in Harvard Ukrainian Studies XII-XIII, 1988/1989 (Proceedings of the International Congress Commemorating the Millenium of Christianity in Rus'-Ukraine, éds. Omeljan Pritsak et Ihor Ševčenko), (1990), 65. ${ }^{2}$ Legenda Sancti Gerardi episcopi (Vita Sancti Gerardi) est une ample œuvre hagiographique qui a comme sujet la vie et l'activité du Gérard de Sagredo (977/980-1046). En 1030, après la défaite du voïevode Ajtony, Gérard est devenu l'évêque titulaire du nouveau diocèse de Csanád. Le texte de la biographie de l'évêque Gérard de Csanád a été conservé sous trois formes de base : la Légende reflétée dans les images, Legenda minor et Legenda maior. Selon l'opinion des historiens magyars, partagée par les chercheurs roumains aussi, les deux Legendae ont été elaborées, quelque part, dans l'intervalle situé entre la fin du $\mathrm{XI}^{\mathrm{e}}$ siècle et la moitié du XII siècle, dans le contexte de l'élaboration des premiers textes à caractère hagiographique de la Hongrie médiévale. Legenda maior constitue un développement de la Legenda minor, texte rendu définitif au XIV ${ }^{\mathrm{e}}$ siècle. Il est la version utilisée de préférence par les médiévistes; pour la discussion concernant la datation des versions de la Légende de Saint Gérard, voir Șerban Turcuș, Sfântul Gerard de Cenad sau despre destinul unui venețian în jurul anului 1000, [Saint Gérard de Csanád ou sur la destin d'un vénetien vers l'an 1000] (București: Carom, 2004), 36-39.

${ }^{3}$ L'oeuvre Deliberatio Gerardi Moresenae Ecclesiae Episcopi supra Hymnum Trium Puerorum ad Isingrinum Liberalem se présente sous la forme d'un traité théologique et philosophique dedié à « Isingrim le maître », sans doute un personnage fictif. On ne connaît pas la date exacte de l'élaboration de l'ouvrage, qui a subi des changements successifs jusqu'à la dernière année de la vie de Gérard (1046), voir Radu Constantinescu (éd.), Gerard din Cenad: Armonia lumii sau tălmăcire a cântării celor trei coconi către Insingrim dascălul, [Gérard de Csanád: L'Harmonie du monde ou interprétation du chant des trois garçons dedié à Isingrim le maître] (București: Meridiane, 1984), 158-159 ; sur la traité Deliberatio, voir aussi Előd Nemerkényi, Latin Classics in Medieval Hungary eleventh Century, (Debrecen-Budapest: 2004), 73-156.
} 


\section{R. M. Feraru \\ L'Église et l'État en Hongrie dans la première moitié du XIe siècle, avec un regard spécial sur Legenda 38 \\ Sancti Gerardi et Deliberatio}

siècle et leurs implications sur le plan politique, idéologique et religieux. En même temps, nous nous proposons - sur la base des renseignements donnés par les sources - de découvrir la relation entre Saint Gérard et les trois rois magyars, Étienne I ${ }^{\mathrm{er}}$, Pierre Orseolo et Aba Sámuel.

\section{Le grand-prince Géza et la christianisation des Hongrois}

Après avoir consolidé leur pouvoir dans leur nouvelle patrie, les Hongrois ont déclenché de nombreuses expéditions de pillage tant dans l'Europe occidentale et centrale, que dans l'Europe du Sud-Est. Le 10 août 955, l'empereur Otton $\mathrm{I}^{\mathrm{er}}$ a remporté la victoire contre les Hongrois dans la bataille de Lechfeld. Cette défaite fut fatale pour les Magyars, qui n'ont plus osé initier des raids de pillage contre le centre et l'ouest de l'Europe.

Mais comme la christianisation des Magyars ne fut plus une priorité pour Byzance ${ }^{4}$, après 955 , ils se tournèrent vers l'Église de Rome. En 963, le chef tribal Taksony manda une délégation à Rome pour demander la nomination d'un évêque qui puisse entreprendre une action d'apostolat parmi les Magyars païens. Le pape Jean XII confia alors à l'évêque Zachée la mission d'évangéliser les Magyars, mais l'empereur Otton $\mathrm{I}^{\text {er }}$ (936-973) empêcha celui-ci d'entrer en Pannonie ${ }^{5}$. Le geste de l'empereur s'explique par le fait que, après la défaite des Magyars à Lechfeld (955), il s'érigea non seulement comme défenseur du monde chrétien, mais aussi comme responsable de l'expansion missionnaire parmi les populations païennes de l'Europe orientale. Plus précisément, Otton $I^{\text {er }}$ a assumé la mission d'évangéliser ces populations, voulant ainsi se substituer à la papauté. L'empereur avait obtenu même le soutien de l'Église allemande qu'il avait transformée en une institution centrale de son gouvernement. Otton $\mathrm{I}^{\mathrm{er}}$ avait élaboré un système ecclésiastique impérial - le soi-disant Reichskirchensystem - au cadre duquel les évêques, investis par le monarque, recevaient différentes dignités politiques, étant considérés comme vicaires impériaux et fonctionnaires de l'État. Il recrutait les conseillers parmi les ecclésiastiques, auxquels il accordait en échange de nombreux privilèges et immunités. C'est ainsi que la nouvelle organisation ecclésiastique était fondée sur la convergence entre sacerdotium et regnum. L'Église était devenue l'instrument le plus important pour l'exercice du pouvoir au cadre de l'État des successeurs d'Otton le Grand et des monarques saliens ${ }^{6}$.

L'objectif d'Otton $\mathrm{I}^{\text {er }}$ était que les évêques chargés d'évangéliser les peuples païens de l'Europe orientale soient envoyés non par le pape, mais par l'empereur. La raison de cette politique était d'obtenir la soumission envers la cour impériale de ces princes païens et de leurs sujets, tous désireux

\footnotetext{
${ }^{4}$ Pour arrêter les attaques dévastatrices des Magyars qui avaient lieu sur les territoires byzantins, l'empereur Constantin VII Porphyrogénète (913-959) conclut avec les tribus magyares une alliance de type clientélaire par laquelle il s'obligeait à leur accorder un tribut annuel; il s'agissait de dons offerts régulièrement aux chefs tribaux. L'alliance avec les Magyars fut scellée par la conversion au christianisme des chefs tribaux Termatzu et Bulcsu en 948 et respectivement Gyula en 953. La défaite des Magyars à Lechfeld (955) où perdit la vie leur chef même Bulcsu, qui était le principal allié des Byzantins, a compromis en totalité la christianisation des Magyars par Byzance. Dans ces conditions, le basileus décida d'arrêter le paiement du tribut aux chefs magyars ce qui déclencha les hostilités entre Byzance et Magyars. Vers 957, probablement, avec la conversion au christianisme de la princesse russe Olga de Kiev, Byzance décide d'orienter la direction d'évangélisation vers l’Europe orientale, plus précisément vers l'espace russe, vezi Györffy, « La christianisation », 66-67.

${ }^{5}$ Scriptores rerum germanicarum: Liudprandi opera, éd. Joseph Becker (Hannover und Leipzig: Hahnsche Buchhandlung, 1915), VI, 163: « [...] et Zacheum virum reprobatum, divinarum atque humanarum inscium litterarum a domno papa episcopum noviter consecratum et Ungariis ad praedicandum ....».

${ }^{6}$ Alexandru-Florin Platon, Laurențiu Rădvan, Bogdan-Petru Maleon, $O$ istorie a Europei de Apus in Evul Mediu. De la Imperiul Roman târziu la marile descoperiri geografice (secolele V-XVI), [Une histoire de l'Europe de l'Ouest dans le Moyen Âge. De l'Empire romain tardif aux grandes découvertes géographiques (Ve-XVI siècles)] (Iași: Polirom, 2010), 205.
} 
de conversion. C'est pourquoi Otton le Grand a mis au point - par l'intermédiaire de son archichapelain, l'archevêque de Mayence, et dans le but spécial d'évangéliser ces princes et les territoires qu'ils contrôlaient - une procédure de consécration d'un moine d'une abbaye impériale (Reichsabtei) ${ }^{7}$.

La christianisation systématique des Magyars commença avec le règne du duc Géza (972-977) qui a sollicité dans ce but l'aide de l'empereur Otton I ${ }^{\mathrm{er}}$. Le prince Géza ne s'adressa à l'empereur pour lui solliciter un évêque qu'après avoir appris le mariage - célébré à Rome en 972 - entre Otton II (973983), fils d'Otton $\mathrm{I}^{\text {er }}$, et la princesse byzantine Théophano, nièce de l'empereur byzantin Jean Tzimiskès. Ce mariage devait affermir l'alliance entre les deux Empires rivaux. Vu cette conjoncture défavorable, Géza était obligé de se chercher un protecteur; il se rendait très bien compte que cette alliance constituait une menace à l'adresse de la Hongrie, qui était entourée des deux Empires, le Saint-Empire romain germanique et l'Empire byzantin ${ }^{8}$.

L'empereur Otton ${ }^{\text {er }}$ répondit avec promptitude à la sollicitation du prince Géza. En 973, par l'intermédiaire de l'évêque Pilgrim de Passau, Otton ${ }^{\mathrm{er}}$ fit venir en Hongrie le moine Bruno-Prunward du monastère Saint-Gall. Celui-ci fut, sans doute, sacré évêque à la demande de l'empereur, en qualité de membre d'une abbaye impériale, par l'archevêque de Mayence. D'ailleurs, l'évêché de Passau considérait dès lors l'ancienne Pannonie comme sa zone d'influence ${ }^{9}$. Bruno-Prunward baptisa le prince Géza et les membres de sa famille ; parmi ceux-ci se trouvait Vajk, le fils de Géza et de Sarolt, baptisé en 996 sous le nom d'Étienne. Mais les légendes et les chroniques magyares du XI siècle attribuent à l'évêque Adalbert de Prague la conversion de Vajk-Étienne. Cette information est infirmée par l'œuvre Vie de Saint Adalbert, écrite par Bruno de Querfurt, qui relate que c'est l'évêque de Prague qui a envoyé ses représentants en Pannonie; ce fut lui, personnellement, qui se rendit en Hongrie pour s'y établir vers 995 , mais il ne réussit pas à convertir à la foi chrétienne les chefs tribaux magyars $^{10}$.

L'évêque Bruno-Prunward avec les autres prêtres missionnaires envoyés par l'évêché de Passau convertirent au christianisme environ 5000 Hongrois. Les sources nous informent que le prince Géza a soutenu l'action d'évangélisation initiée par Bruno, comprenant que la collaboration avec l'Église

\footnotetext{
${ }^{7}$ L'exemple le plus significatif est en ce sens la consécration, en 961, d'Adalbert, moine du monastère Saint Maxime de Trier, dans le but de diriger une mission d'évangélisation en Russie. Après l'échec de sa mission à Kiev, Adalbert deviendra le premier archevêque de Magdebourg et, dans cette qualité, il enverra, en 968, une mission chez le prince polonais Mieszko, mission dirigée par l'évêque Iordan, Györffy, " La christianisation », 68; Idem, "Structures ecclésiastiques de la Hongrie médiévale », Miscellanea historiae ecclesiasticae V, (Colloque de Varsovie, octobre 1971), (1974), 160-161; voir aussi Jacques Brosse, Histoire de la Chrétienté d'Orient et d'Occident, de la conversion des barbares au sac de Constantinople, (406-1204), (Paris: Albin Michel, 1995), 757.

${ }^{8}$ Györffy, « La christianisation », 68; Idem, « Structures ecclésiastiques », 161; pour les relations entre l'Empire romain germanique et Byzance, voir Platon, Rădvan, Maleon, O istorie a Europei de Apus, 199.

${ }^{9}$ Ibid., 68; Györffy, « Structures ecclésiastiques », 161; Turcuș, Sfântul Gerard de Cenad, 23; Jerzy Kloczowski «La nouvelle chrétienté du monde occidental. La christianisation des Slaves, des Scandinaves et des Hongrois entre le $\mathrm{IX}^{\mathrm{e}}$ et le $\mathrm{XI}^{\mathrm{e}}$ siècle ", Histoire du christianisme des origines à nos jours, IV: Evêques, moines et empereurs (610-1054), éd. Jean-Marie Mayeur, et al. (Paris: Desclée, 1993), 891.

${ }^{10}$ Ibid., 69; Turcuș, Sfântul Gerard de Cenad, 24-25; Gyula Kristó, Histoire de la Hongrie médiévale, Tome I: Le temps des Árpáds, préface de Sándor Scernus et Noël-Yves Tonnerre, traduit du hongrois par Chantal Philippe, (Rennes: Presses Universitaires de Rennes, 2000), 36; cf. Brosse, Histoire de la Chrétienté, 757 ; à propos de l'activité de Saint Adalbert en tant que missionnaire en Hongrie, voir récemment Marianne Sághy, «Aspects de la christianisation des Hongrois aux IX ${ }^{\mathrm{e}}-\mathrm{X}^{\mathrm{e}}$ siècles », Early Christianity in Central and East Europe (Congress of Commission Internationale d'Histoire Ecclésiastique Comparée, Lublin 2-6 septembre 1996), éd. P. Urbańczyk, (Warszawa: 1997), 60-64.
} 
contribue à affermir son autorité politique ${ }^{11}$. En 996, le prince Géza fonda le Pannonhalma, premier monastère de rite latin de Pannonie, d'après le modèle du monastère de Břevnov-Prague, fondé par le Saint Adalbert. Radla, collègue d'études et ami de Saint Adalbert, fut nommé premier abbé de ce monastère; on suppose que, ultérieurement, Radla devint le deuxième évêque des Magyars sous le nom de Sébastien ${ }^{12}$. L'acte de la christianisation des Magyars par Bruno-Prunward - acte soutenu par Géza et souvent accompli par l'utilisation de moyens de conversion violents, a eu un caractère politique, reliant définitivement la Hongrie à l'Occident européen.

\section{La politique religieuse d'Étienne $\mathbf{I}^{\mathrm{er}}$}

Le prince Géza désigna comme successeur au trône son fils Étienne. En 996, Étienne épousa Gisèle, la fille du prince bavarois Henri II dit « le Querelleur », devenant ainsi le beau-frère d'Henri IV, le nouveau duc de Bavière (995-1002) et futur empereur de l'Empire romain germanique (1002-1024) ${ }^{13}$. Le mariage d'Étienne avec Gisèle a contribué ainsi tant au renforcement de son pouvoir politique qu'à la christianisation de rite latin de la Hongrie. Grâce à sa femme, Étienne établit des liens très forts avec le duché de Bavière et l'Église romaine. Il accueillit en Hongrie des prêtres bavarois - qui faisaient partie de la suite de Gisèle - et de nombreux missionnaires et chevaliers allemands ${ }^{14}$.

La mort de Géza (997) engendra une vive dispute pour le trône, dont les protagonistes furent Étienne, le fils de Géza, et Koppány, le fils de Tar Szerénd, descendant de la famille dynastique d'Árpád. En qualité du plus âgé descendant masculin de la maison d'Árpád, Koppány revendiqua alors le pouvoir suprême. En même temps il demanda la main de la princesse veuve Sarolt, mère d'Étienne, selon la très ancienne habitude païenne du lévirat ${ }^{15}$. Dans sa dispute avec Koppány, Étienne avait joui du soutien des chevaliers allemands, amenés de Bavière par sa femme Gisèle. Dans la confrontation entre les deux leaders hongrois, Étienne représentait l'organisation étatiste et le christianisme et Koppány, la liberté tribale et le paganisme. La bataille décisive entre Étienne et Koppány - qui eut lieu à Veszprém - finit par la victoire du premier ${ }^{16}$.

\section{A. Le couronnement d'Étienne $I^{e r}$ comme roi « apostolique » des Hongrois}

En 998-999, après la défaite de son rival Koppány, Étienne entreprit des démarches auprès du pape Sylvestre II pour obtenir la couronne royale. Il voulait, en même temps, obtenir l'acceptation et le soutien du pape pour l'organisation de l'Église en Hongrie. Étienne fut obligé de demander le soutien de l'Église de Rome, car il craignait, à juste raison, de devenir le vassal de L'Empire ottonien s'il avait sollicité l'aide de l'empereur pour le couronnement ${ }^{17}$.

Selon les affirmations de l'évêque Thietmar de Mersebourg, le chroniqueur du règne d'Otton III, «Vajk, le beau-frère d'Henri, duc de Bavière, après avoir fondé des évêchés dans son royaume, reçut une couronne et des bénédictions par la faveur de l'empereur et grâce à ses recommandations ${ }^{18}$.

\footnotetext{
${ }^{11}$ Ibid., 69; Kristó, Histoire I, 33-34.

${ }^{12}$ Györffy, «La christianisation », 70; Turcuș, Sfântul Gerard de Cenad, 28; Kristó, Histoire I, 36;

${ }^{13}$ Kristó, Histoire I, 35; Platon, Rădvan, Maleon, O istorie a Europei de Apus, 203.

${ }^{14}$ Ibid., 36; Platon, Rădvan, Maleon, O istorie a Europei de Apus, 343.

15 Ibid., 36.

${ }^{16}$ Ibid., 36-37.

${ }^{17}$ Ibid., 38.

${ }^{18}$ Die Chronik des Bischofs Thietmar von Merseburg und ihre Korveier Überarbeitung, éd. Robert Holtzmann, (Monumenta Germaniae Historica Scriptores. Nova Series), (Berlin: Weidmann, 1935), IV, 59, 199 (anul 1001):
} 
Malgré l'expression ambiguë et tendancieuse de Thietmar, il n'y a aucun doute qu'Étienne n'eût pu obtenir la couronne royale et les bénédictions que du pontife romain ${ }^{19}$. Cependant, il ne faut pas oublier que le pape avait accordé à Étienne la couronne et sa bénédiction par la faveur de l'empereur Otton III et grâce à sa recommandation.

En 999, par la volonté d'Otton III, son précepteur Gerbert, originaire d'Aurillac (en Auvergne) était devenu pape sous le nom de Sylvestre II (999-1003) ${ }^{20}$. Otton III avait trouvé en Sylvestre II un allié prêt à placer l'autorité papale au service de son projet de restauration de l'Empire romain (renovatio imperii). L'empereur avait adopté l'interprétation romaine de l'idée d'empire, revendiquant ainsi le pouvoir universel. Il s'était proclamé empereur romain (Imperator Augustus Romanorum) et avait établi sa résidence officielle à Rome, sur le mont Palatin $(998)^{21}$. De plus, l'idéologie politique ottonienne avait récupéré, à quelques modifications près, la théologie chrétienne du pouvoir impérial, élaborée au $\mathrm{IV}^{\mathrm{e}}$ siècle par Eusèbe de Césarée. Par analogie avec la conception d'Eusèbe, l'Empire romain germanique était conçu comme imperium christianum; il devait réunir l'ensemble du peuple chrétien, c'est-à-dire l'Église, au sens large et intégral du terme.

L'empereur exerçait un pouvoir donné par Dieu et, tout en étant une image de celui-ci (imago Dei), il était considéré comme son instance unique et universelle de gouvernement ; en vertu de son pouvoir absolu, sa compétence s'étendait tant sur l'empire que sur l'Église, tant sur les laïques que sur les ecclésiastiques. La nature quasi-sacerdotale du pouvoir du monarque lui donnait la qualité de «chef » (caput) et protecteur de l'Église, ce qui justifiait son intervention dans les problèmes de l'Église, tandis que la souveraineté du pape était limitée au domaine religieux seul. En qualité de «serf des Apôtres » (servus Apostolorum) et de « serf de Jésus-Christ » (servus Christi), l'empereur s'assumait une primauté incontestable dans le monde chrétien. Il avait ainsi le droit de diriger l'ensemble de l'oekoumène chrétien, plus précisément la totalité des terres chrétiennes et de celles qui étaient en train d'être christianisées ${ }^{22}$.

Revenant à l'événement du couronnement d'Étienne, il est fort probable que le pape Sylvestre II a accordé les insignes de la royauté au grand-prince magyar au vu et au su d'Otton III. Cette réalité est confirmée par une légende conservée dans La Vie de Saint Étienne (Legenda Sancti Stephani), écrite par l'évêque Hartvic, vers l'an 1100. Selon ce que relate Hartvic, le prince Étienne aurait délégué l'abbé Astrik pour qu'il aille à Rome dans le but de demander au pape la couronne royale et son consentement pour pouvoir fonder des évêchés ainsi qu'un archevêché à Esztergom. À la veille de l'arrivée de l'émissaire des Magyars, le pape Sylvestre eut un rêve : un ange fit son apparition pour l'avertir que l'émissaire d'un peuple inconnu allait se présenter devant lui. En même temps, l'ange conseilla au pontife romain d'accorder la couronne royale au prince des Hongrois. Après avoir écouté le rapport d'Astrik sur l'œuvre d'évangélisation menée par Étienne, Sylvestre II aurait envoyé au jeune prince non seulement la couronne royale, mais aussi une croix ; le pape aurait affirmé : « Moi, je suis

« Imperatoris autem predicti gracia et hortatu gener Hinrici, ducis Bawariorum, Waic in regno suo episcopales cathedras faciens, coronam et benedictionem accepit ».

${ }^{19}$ Marianne Sághy, « L'organisation des Églises en Hongrie autour de l'An Mil : Le cas de l'évêché de Csanád ", Archivum Bobiense - Studia IV: Gerberto d'Aurillac da abate di Bobbio a papa dell'anno 1000, (Atti del Congresso internationale, Bobbio, 28-30 settembre 2000) éd. Flavio G. Nuvolone, (Bobbio: Associazione culturale Bobbio / Pc; Amici di Archivum Bobiense, 2001), 472.

${ }^{20}$ Bertrand Fauvarque, "Sylvestre II et Otton III : politique, réforme et utopie. Aspects eschatologiques », Archivum Bobiense - Studia IV: Gerberto d'Aurillac da abate di Bobbio a papa dell'anno 1000, (Atti del Congresso internationale, Bobbio, 28-30 settembre 2000) éd. Flavio G. Nuvolone, (Bobbio: Associazione culturale Bobbio / Pc; Amici di Archivum Bobiense, 2001), 558-561.

${ }^{21}$ Fauvarque, « Sylvestre II et Otton III », 548-549; Platon, Rădvan, Maleon, O istorie a Europei de Apus, 203.

${ }^{22}$ Ibid., 567 ; 577-579 ; Platon, Rădvan, Maleon, O istorie a Europei de Apus, 204. 
apostolique, mais lui, il est vraiment apôtre du Christ, si Christ a pu convertir tant de peuples par lui. C'est pourquoi, nous lui laissons la possibilité de disposer des églises et de ses peuples selon les deux lois $»^{23}$.

Le premier jour du nouveau millénaire chrétien (le 25 Décembre 1000), le prince Étienne fut oint roi des Hongrois par Astrik - nommé légat papal pour la Pannonie - dans l'Église Saint Adalbert d'Esztergom. Astrik remit au premier roi magyar les insignes du pouvoir royal, la lance et la couronne, envoyées par le pape Sylvestre II. Le couronnement d'Étienne I ${ }^{\text {er }}$ consacra ainsi la fondation du Royaume magyar chrétien qui eut lieu en même temps que celle de l'Église. On suppose que la confirmation de l'investissement d'Étienne $I^{\text {er }}$ et la décision concernant l'organisation de l'Église magyare aient été approuvées au cadre du synode de Ravenne, du 4 avril 1001, lequel eut lieu dans la basilique Sant'Apollinare in Classe. À cette occasion, le pape Sylvestre II - en présence de l'empereur Otton, de l'abbé Odilon de Cluny et des ermites de Pereum, Bruno de Querfurt et Romuald - a signé la Charte de fondation de l'Église hongroise ${ }^{24}$. Le premier archevêché de Hongrie fut fondé, conformément au désir du roi Étienne I ${ }^{\mathrm{er}}$, à Esztergom (Strigonium / Gran) en 1001. La fondation d'un archevêché à Esztergom - qui était la résidence royale d'Étienne - reflétait le désir du roi magyar de réunir de cette manière le centre du pouvoir royal et la capitale religieuse du pays ${ }^{25}$.

Le couronnement d'Étienne et la fondation de l'Église magyare n'ont été accompagnés d'aucune prétention de suzeraineté, ni de la part de l'empereur, ni de la part du pape. L'organisation d'une Église magyare indépendante « portait une grave atteinte aux intérêts de l'Église impériale », ce qui explique l'absence du synode de Ravenne des archevêques et des évêques allemands ${ }^{26}$. Donc, l'investissement d'Étienne comme roi de Hongrie et la fondation de l'Église magyare représentent les premiers fruits de la politique concertée de l'empereur Otton III et du pape Sylvestre II.

\section{B. L'organisation de l'Église magyare}

Les vies de Saint Étienne rédigées à la fin du $\mathrm{XI}^{\mathrm{e}}$ siècle ainsi que les homélies composées en l'honneur $\mathrm{du}$ roi lui attribuaient le rôle d'apôtre et d'évangélisateur de la Hongrie ${ }^{27}$. Dans la collection d'enseignements adressés par le roi magyar à son fils Émeric (Libellus de institutione morum), Étienne, expliquait à ce dernier, qu'en vertu de sa signification étymologique, le qualificatif

\footnotetext{
${ }^{23}$ « Legenda Sancti Stephani regis ab Hartvico episcopo conscripta », in Scriptores rerum Hungaricarum tempore ducum regumque stirpis Arpadianae gestarum, éd. E. Szentpétery, (Budapest: 1938), II, 412-414: « [...] sum apostolicus, ille vero merito Christi apostolus, per quem tantum sibi populum Christus convertit. Quapropter dispositioni eiusdem, prout divina ipsum gratia instruxit, ecclesias simul cum populis utroque iure ordinandas relinquimus », apud, Sághy, « L’organisation des Églises », 473, nota 6.

${ }^{24}$ Le synode de Ravenne du mois d'avril 1001 fut précédé d'un autre synode qui eut lieu le $1^{\text {er }}$ janvier 1001 au monastère S. Maria in Pallara de Rome. À cette occasion, le pape Sylvestre II, l'empereur Otton III et le duc de Bavière, Henri IV, prirent en discussion l'organisation de l'Église magyare et le titre qui allait être accordé au grand prince Étienne, voir en ce sens, Heinz Wolter, Die Synoden im Reichsgebiet und in Reichsitalien von 916 bis 1056, (München-Wien: F. Schöningh, 1988), 189-196, apud Sághy, « L’organisation des Églises », 474.

${ }^{25}$ József Török, , « Il primo re d'Ungheria e l'organizzazione della Chiesa ungherese », Archivum Bobiense Studia IV: Gerberto d'Aurillac da abate di Bobbio a papa dell'anno 1000, (Atti del Congresso internationale, Bobbio, 28-30 settembre 2000) éd. Flavio G. Nuvolone, (Bobbio: Associazione culturale Bobbio / Pc; Amici di Archivum Bobiense, 2001), 458, 459, 460-461.

${ }^{26}$ Sághy, «L'organisation des Églises », 474; vezi și László Koszta, «L'organisation de l’Église chrétienne en Hongrie ", dans Les Hongrois et l'Europe. Conquête et intégration, éd. S. Csernus, K. Korompay, (Paris-Szeged: 1999), 300.

${ }^{27}$ L'homélie De Sancto Stephano loue la conversion des magyars «païens » («gentils») qui deviennent « des humains " grâce à leur saint roi, apôtre et législateur, voir Dominique Iogna-Prat, " Constructions chrétiennes d'un espace politique», Le Moyen Age. Revue d'histoire et de Philosophie, 1, (2001): 66.
} 
d'augustus, attaché au titre de rex, obligeait le roi à faire accroître (augere) l'Église, ce qui signifiait que sa fonction était celle de contribuer à l'extension du royaume et de la chrétienté (christianitas) ${ }^{28}$. La même source citée plus haut - Libellus de institutione morum - incluait le cliché selon lequel l'image de l'Église comme corps du Christ se reflétait dans l'Église et le royaume magyars ${ }^{29}$.

L'organisation de l'Église dans la Hongrie médiévale fut presque exclusivement l'œuvre du roi Étienne $\mathrm{I}^{\text {er }}$. Legenda maior de Saint Étienne relate que le roi, en vertu de sa délégation apostolique, avait fondé des évêchés et des monastères ${ }^{30}$. Il avait créé dix évêchés et un archevêché, Esztergom ; pendant son règne, les églises, les chapitres et les monastères fleurissent partout et de nombreux clercs, atteints du Saint Esprit, quittent leurs sedes propriae pour se mettre au service du roi-apôtre. Étienne I fit ériger, à l'endroit appelé « le mont sacré» (Pannonhalma), un monastère placé sous la protection de Saint pape Martin, qui protège le royaume magyar à côté de Georges, guerrier et martyr, de la Vierge Marie, à qui le roi consacre la Hongrie, et à côté, bien sûr, du Christ auquel Étienne lui-même s'identifie in ore, in corde et in cunctis actibus ${ }^{31}$.

L'organisation administrative territoriale de l'Église dépendait du contrôle que le roi exerçait sur le territoire du royaume. «L'Église magyare, créée grâce aux donations foncières du roi ou bien, grâce aux territoires conquis sur les ennemis fut par excellence une Eigenkirche ${ }^{32}$.

L'organisation territoriale des évêchés, initiée par Étienne $\mathrm{I}^{\mathrm{er}}$ dès le début de son règne, fut réalisée en même temps que l'organisation administrative du Royaume magyar en comitats (comitatus). Le territoire du royaume fut divisé en 50 comitats; ceux-ci avaient été créés autour des forteresses confisquées aux chefs des clans magyars et aux territoires qui en dépendaient. Les territoires des 50 comitats correspondaient, en grandes lignes, aux zones contrôlées initialement par les chefs des 50 clans des tribus magyares et khazares qui avaient conquis la Pannonie ${ }^{33}$.

Chaque comitat comprenait un territoire bien délimité, ayant pour centre un endroit fortifié qui servait comme siège pour un comte (ispán) nommé par le roi. Saint Étienne confia l'administration des comitats aux membres de sa famille ; ainsi, Doboka, père de Csanád, administrait le comitat du même nom, créé au nord de la Transylvanie après 1003 ; à Csanád, neveu d'Étienne $\mathrm{I}^{\text {er }}$, on confia le comitat de Csanád, fondé sur le territoire où régnait le duc Ajtony. Zoltan fut nommé ispán du comitat Féher, ayant pour résidence Alba-Iulia (Gyulafehérvár) en Transylvanie, arrachée au prince Gyula. En échange, le prince Émeric, fils du roi, avait sa résidence à Biharea (Nagyvárad) ${ }^{34}$.

La plupart des évêchés créés par Saint Étienne avaient pour siège une fortification, où habitait soit un membre de la famille royale, soit un de ses proches, et ceux-ci devaient administrer le territoire qui leur était confié. Entourés par leurs suites armées, ces ducs assuraient la sécurité de l'activité missionnaire des évêques et de leur Église ${ }^{35}$. Mais, l'organisation de l'Église s'appuyait aussi sur les résidences fortifiées des comtes. Aux alentours des forteresses, sous la protection des comtes, furent créées les premières paroisses qui devinrent au $\mathrm{XI}^{\mathrm{e}}$ siècle les résidences des diacres et des archidiacres. Cela explique pourquoi en Hongrie le territoire des archidiaconés correspondait, dans la majorité des

\footnotetext{
${ }^{28}$ Iogna-Prat, « Constructions chrétiennes », 66.

${ }^{29}$ Ibid., 62.

${ }^{30}$ Ibid., 66-67.

31 «Legenda Sancti Stephani », 683, 381, 387, 392, apud Iogna-Prat, « Constructions chrétiennes », 66, les notes 67 și 69.

${ }^{32}$ Sághy, « L’organisation des Églises », 474.

${ }^{33}$ Györffy, « Structures ecclésiastiques », 162 ; Idem, « La christianisation », 73; Kristó, Histoire I, 43.

${ }^{34}$ Idem, « La christianisation », 73; Kristó, Histoire I, 44-46.

${ }^{35}$ Idem, « Structures ecclésiastiques », 161; Kristó, Histoire I, 46-48.
} 


\section{\begin{tabular}{l|l} 
R. M. Feraru & 44
\end{tabular} \\ L'Église et l'État en Hongrie dans la première moitié du XIe siècle, avec un regard spécial sur Legenda \\ Sancti Gerardi et Deliberatio}

cas, au territoire des comitats ${ }^{36}$. Les sièges des évêchés magyars se situent dans les parties centrales du royaume, ce qui prouve que l'idée de consolidation interne de l'État a été l'un des facteurs décisifs dans le choix des sièges épiscopaux. Un autre aspect remarquable de l'organisation ecclésiastique du Royaume magyar concerne la configuration géographique des territoires des évêchés qui se déployaient en éventail vers les régions périphériques du Bassin des Carpates. Les diocèses magyars avaient des frontières ouvertes vers les périphéries du royaume, ce qui facilitait l'extension immédiate de leur contrôle sur les nouveaux territoires conquis. D'ailleurs les historiens du Moyen Âge sont unanimes à accepter que la configuration des diocèses ecclésiastiques situés à l'est de la rivière Tisza (fr. Theisse ou Teysse) se réalisa au fur et à mesure de l'extension vers le Bassin des Carpates (en Transylvanie et dans le Banat) du territoire conquis par les Magyars et de l'organisation dans cet espace des comitats de frontière (en hongrois határvármegye), dont la principale tâche était la défense des frontières orientales du royaume ${ }^{37}$.

Le plan de création des diocèses, influencé par la collection Pseudo-Isidorienne, très répandue à l'époque, prescrit l'installation d'un siège métropolitain et de dix ou douze évêchés, pour former une province ecclésiastique (provincia) ${ }^{38}$. Étienne $\mathrm{I}^{\mathrm{er}}$ suivit ce plan pour organiser l'Église magyare. Selon la tradition magyare, pendant ses 41 ans de règne, le roi aurait créé 10 évêchés et 2 archevêchés ${ }^{39}$. Le roi acheva le projet en trois étapes. En une première étape, comprise entre 997 et 1003, furent fondés les évêchés de Veszprém (997/1000) ${ }^{40}$, d'Esztergom (1001), de Györ (1003) et, probablement, de Transylvanie (après 1001/1003). Dans la deuxième étape, furent fondés les évêchés de Pécs ${ }^{41}$, d'Eger et de Kalocsa. Dans la troisième étape, le roi Étienne I ${ }^{\text {er }}$ fonda l'évêché de Csanád (1030), dont le vénitien Gérard de Sagredo fut le premier évêque (1030-1046) ${ }^{42}$. Après la défaite du duc Ajtony - dont le pouvoir s'exerçait, en grandes lignes, dans la partie sud-ouest de l'actuelle Roumanie - défaite infligée par l'armée magyare dirigée par Chanadinus (1028), le roi Étienne $\mathrm{I}^{\mathrm{er}}$ imposa petit à petit son autorité sur le territoire conquis. Il entreprit l'organisation ecclésiastique du territoire pris en

\footnotetext{
${ }^{36}$ Idem, « Structures ecclésiastiques », 162 ; Idem, « Les débuts de l'évolution urbaine en Hongrie (à suivre) », Cahiers de civilisation médiévale, 46, (1969), 140 ; Kristó, Histoire I, 47.

${ }^{37}$ László Koszta, «State Power and Ecclesiastical System in Eleventh Century Hungary. (An Outline to the Dynamics of the Development of Hungarian Christian Church) ", dans "In my spirit and thougth I remained a European of Hungarian origin". Medieval Historical Studies in Memory of Zoltan J. Kosztolnyik, éds. István Petrovics, Sándor László Tóth, Eleanor A. Congdon, (Szeged: JatePress, 2010), 72; Kristó, Histoire I, 45.

${ }^{38}$ Horst Fuhrmann, « Provincia constat duodecim episcopatibus », Studia Gratiana, XI, (1967), 394-398.

39 «Legenda maior. Vita Sancti Gerardi, Moresanae ecclesiae episcopi » dans Documente privitoare la istoria Mitropoliei Banatului, [Documents concernant l'histoire d'archêveché du Banat] éds. Ioan D. Suciu, Radu Constantinescu, (Timișoara: Mitropolia Banatului, 1980), 11, 30: « ... nunc enim voluntatis meae fuit ut duodecim episcopatus, quos in regno meo statuere decreveram, episcopis implerem » (« car maintenant, je pense nommer par décret des évêques dans les douze évêchés que j’ai voulu fonder dans mon royaume »).

${ }^{40}$ Selon l'historien magyar Gyula Kristó « il est possible que l'évêché de Veszprem soit créé dans les dernières années du prince Géza ». D'après d'autres sources, l'évêché de Veszprém fut fondé par la princesse bavaroise Gisèle, femme d’Étienne $\mathrm{I}^{\mathrm{er}}$. Sa grande étendue confirme la primauté de Veszprém parmi les évêchés magyars. En 1009, le territoire de Veszprém englobait certains comitats qui, plus tard, furent subordonnés à Esztergom, Kristó, Histoire I, 36, 46; Sághy, « L’organisation des Églises », 473; Török, « Il primo re d'Ungheria », 459-460.

${ }^{41}$ Conformément à la charte de fondation, l'évêché de Pécs fut créé le 23 août 1009 . Il fut sacré par l'évêque Azo de Ostie, le légat du pape Jean XX : «... nos [Stephanus Hungarie rex] cum consensu sanctissimi apostolici et in presencia eius nuncii Azonis episcopi ... », voir Przemysław Nowak, « Das Papsttum und Ostmitteleuropa (Böhmen - Mähren, Polen, Ungarn, vom ausgehenden 10. bis zum Beginn des 13. Jahrhunderts) mie einer Neuedition von JL 9067 », dans Rom und Die Regionen. Studien zur Homogenisierung der lateinischen Kirche im Hochmittelalter, Band 19, Herausgegeben von Jochen Johrendt und Harald Müller, (Berlin/Boston: Walter de Gruyter, 2012), 343, la note 42.

${ }^{42}$ Nowak, « Das Papsttum und Ostmitteleuropa », 343; Koszta, « State Power », 70-71; Kristó, Histoire I, 46-47.
} 
possession précédant ainsi l'organisation politique sous forme de comitat, réalisée probablement au début du XII ${ }^{\mathrm{e}}$ siècle ${ }^{43}$.

\section{Le roi Étienne et l'Église}

Le roi s'est pleinement impliqué dans la vie ecclésiastique et dans l'organisation de l'Église magyare. Dans son premier décret émis au début du règne, Étienne avait imposé l'obligation pour chacun («les plus grands et les plus petits, les hommes et les femmes ») d'aller à l'Église, le dimanche, à l'exception de ceux qui surveillaient le feu ${ }^{44}$. Le roi avait facilité l'accomplissement de ce devoir par ses sujets en faisant bâtir des églises dans les endroits où se tenaient les foires; ainsi, les gens pouvaient-ils se diriger de la foire directement vers l'Église ${ }^{45}$. Le deuxième décret promulgué par Étienne $\mathrm{I}^{\mathrm{er}}$ stipulait l'obligation que l'on construise une église tous les dix villages, ce qui permettait au peuple de participer régulièrement aux offices religieux. Chaque groupe de dix villages devait entretenir l'Église, mettant à la disposition de ses serviteurs, une maison, des domestiques, des chevaux et des vaches. Le roi avait la tâche de doter les lieux de culte de vêtements ecclésiastiques et d'objets spécifiques. Les évêques avaient l'obligation de nommer les prêtres et de munir les églises de livres liturgiques ${ }^{46}$. La participation active du roi et sa bienveillance étaient ressenties à tous les niveaux de l'organisation de l'Église magyare, depuis l'évêché jusqu'aux paroisses des villages.

Le culte de la vierge Marie en qualité de protectrice du Royaume magyar a contribué au développement du culte marial dans la Hongrie médiévale dès le début du $\mathrm{XI}^{\mathrm{e}}$ siècle. Quoiqu'il ne fût devenu populaire en Occident qu'à partir du XII ${ }^{\mathrm{e}}$ siècle, le culte de la Sainte Vierge acquit une importance exceptionnelle dès le commencement du règne d'Étienne $\mathrm{I}^{\mathrm{er}}$; ainsi, les principaux édifices de culte de la Hongrie ont-ils été consacrés à la Mère de Dieu : l'Église familiale qui était aussi le lieu d'enterrement du roi à Székesfehérvár, les cathédrales d'Esztergom et Györ, le monastère bénédictin de Pécsvárad et le monastère de religieuses de Veszprémvölgy ${ }^{47}$. Selon la Legenda maior de Saint Étienne, la Vierge Marie aide le roi dans la lutte contre son rival l'empereur Conrad II le Salique. Finalement, le roi va placer le royaume magyar sous la protection de «Marie, de perpétuelle virginité et mère de Dieu ${ }^{48}$. Chaque année, Saint Étienne participait à côté du clergé à la fête de la Dormition de la Mère de Dieu, célébrée dans l'Albe Royale. À cette occasion, le roi avait décidé le rassemblement des dirigeants magyars qui reconnaissaient son autorité, ainsi que la réunion du synode du clergé magyar ${ }^{49}$. La vénération de la Sainte Vierge, dans sa qualité de protectrice du Royaume

\footnotetext{
${ }^{43}$ Le comitat de Csanád est attesté par les documents á peine dans 1197.

${ }^{44}$ A Szent István, Szent László és Kálmán korabeli törvények és zsinati határozatok forrásai (De fontibus legum et decretorum synodalium e temporibus sancti Stephani, sancti Ladislai et Colomani oriundorum), éd. Levente Zárodszky, (Budapest : 1904), IX, 23 : «A sacerdotibus vero et comitibus commendetur omnibus villicis, ita ut illorum iussu omnes concurrant die dominica ad ecclesiam, maiores ac minores, viri ac mulieres, exceptis qui ignes custodiunt $\gg$.

${ }^{45}$ Le souvenir de cette obligation persiste encore en hongrois où le mot « dimanche » - vasárnap - vient du terme vásárnap, qui signifie « jour de foire, de marché » Györffy, « La christianisation », 73.

${ }^{46}$ A Szent István, éd. L. Zárodszky, II, 1, 153: «Decem ville ecclesiam edificent, quam duobus mansis totidemque mancipiis dotent, equo et iumento, sex bubus et duabus vaccis, XXX minutis bestiis. Vestimenta vero et coopertoria rex prevideat, presbiterum et libros episcopi ».

${ }^{47}$ Gábor Klaniczay, «Rex iustus. Le saint fondateur de la royauté chrétienne », Cahiers d'Études hongroises, 8, (1996), 51-52.

48 « Legenda maior », 16, 35: « Factum est autem postquam beatus rex Stephanus ad lucem fidei Christianae Pannoniam convertisset, eam sub patronicio beatae Virginis resignans ...».

${ }^{49}$ Ibid., 8, 27: « Factum est autem, cum beatus rex Stephanus pro coelebrando festo beatae Virginis annuali Albam venisset, tunc mos erat convocare abates et episcopos, ut sacrae solempnitati simul interessent ».
} 


\section{\begin{tabular}{l|l} 
R. M. Feraru & 46
\end{tabular} \\ L'Église et l'État en Hongrie dans la première moitié du XIe siècle, avec un regard spécial sur Legenda \\ Sancti Gerardi et Deliberatio}

magyar, est attestée surtout dans la Legenda maior de Saint Gérard ${ }^{50}$ ainsi que dans son ouvrage Deliberatio, dans lequel l'évêque de Csanád l'invoque à maintes reprises ${ }^{51}$. La dévotion spéciale de Gérard envers la Vierge Marie s'explique tant par la dévotion que lui accorde le roi Étienne que par l'accent mis sur le culte marial en Occident, aux $\mathrm{X}^{\mathrm{e}}-\mathrm{XI}^{\mathrm{e}}$ siècles, probablement sous l'influence de l'ordre de Cluny ${ }^{52}$. Selon la Legenda maior, au moment de sa mort, le roi Étienne aurait consacré la Hongrie à la Vierge Marie : "Son nom, de Mère du Christ, n'est pas prononcé par la nation hongroise, qui l'appelle seulement la Dame. D'où le nom donné par le Saint roi Étienne de famille de la bienheureuse Vierge. [...] Après que l'heureux roi Étienne avait amené la Pannonie à la lumière de la foi chrétienne, la laissant sous la protection de la bienheureuse Vierge, le jour de la Dormition de la Mère de Dieu, délivré de son corps, il trépassa vers l'éternel repos ${ }^{53}$. Accordant dans sa légende un rôle central au fait qu'au moment de sa mort, le roi Étienne avait mis le pays sous la protection de la Vierge Marie, le biographe de Saint Gérard voulait mettre un contrepoids aux prétentions de la papauté de garder son autorité sur la Hongrie, prétentions dissimulées par une mise en valeur de « la protection » de Saint Pierre. Par cet artifice, l'auteur de la Legenda maior essaye d'amplifier outre mesure la protection de la Sainte Vierge sur le Royaume magyar au détriment de celle de Pierre et de son successeur, le pape ; ainsi, il ne fait autre chose que « contester l'obédience féodale de la Hongrie par rapport au Saint Siège, obédience telle qu'elle avait été contractée par le roi Étienne ${ }^{\mathrm{er}}$ et continuée jusqu'à l'époque de Boniface VIII ${ }^{54}$.

Pendant la deuxième moitié de son règne, d'après le modèle des Francs, le roi Étienne ${ }^{\mathrm{er}}$ a élevé l'Église de Székesfehérvár (Alba Regia) au rang de chapelle royale, la soustrayant à l'autorité de l'évêque. Ainsi, Székesfehérvár est devenu la deuxième ville ecclésiastique de Hongrie après Esztergom et, plus tard, elle fut transformée en sanctuaire dynastique (lieu de couronnement et sépulture) des rois magyars ${ }^{55}$.

Les débuts du monachisme en Hongrie sont liés au règne d'Étienne $\mathrm{I}^{\mathrm{er}}$, auquel on doit la fondation de 10 abbayes, dont 8 bénédictines et 2 basiliennes ou de rite grec ${ }^{56}$. La construction de l'abbaye de Pannonhalma - premier monastère de Hongrie - commencée pendant le règne de Géza et consacrée en 1002, est liée au nom d'Étienne le Saint; à celle-ci viennent s'ajouter encore cinq monastères bénédictins fondés par Étienne I ${ }^{\mathrm{er}}$ : les abbayes de Zalavár (1019), Pécsvárad (1038), Bakoybél (fondée probablement pendant la deuxième moitié du règne d'Étienne $\left.\mathrm{I}^{\mathrm{er}}\right)$, Zobor et Somlóvásárhely ${ }^{57}$.

Le roi Étienne $\mathrm{I}^{\mathrm{er}}$ s'avéra particulièrement tolérant envers les monastères de rite grec oriental de Hongrie, auxquels il avait accordé toute une série de privilèges et même de donations. La charte de donation en faveur du monastère grec de religieuses de Veszprémvölgy représente la preuve la plus

\footnotetext{
${ }^{50}$ Legenda maior du Saint Gérard consacre une chapitre à la Vierge Marie.

${ }^{51}$ Gérard de Csanád, Deliberatio Gerardi Moresenae Ecclesiae Episcopi supra Hymnum Trium Puerorum ad Isingrinum Liberalem éd. Gabriel Silagi (« Corpus Christianorum: Continuatio Mediaevalis » 49), (Turnhout: Brepols, 1978), passim.

${ }^{52}$ On sait que l'abbé Odilon de Cluny (962-1048) était un fervent adorateur de la Vierge Marie, à qui il avait dédié quatre homélies et un hymne, voir Klaniczay, "Rex invictus », 52-53. Selon une information que nous n'avons pas pu vérifier, les détails fournis par le biographe de Saint Gérard seraient susceptibles de suggérer que la dévotion mariale à Csanád suivait les règles observées dans l'Église d'Aquilée, apud, Ioan D. Suciu, Radu Constantinescu (éd.), Documente privitoare la istoria Mitropoliei Banatului, (Timișoara: Mitropolia Banatului, 1980), 61, nota 13.

53 «Legenda maior», 13, $32 ; 16,35$.

${ }^{54}$ Klaniczay, «Rex iustus », 52; Turcuș, Sfântul Gerard de Cenad, 110-111.

${ }^{55}$ Kristó, Histoire I, 47; Györffy, « Structures ecclésiastiques », 162-164.

${ }^{56}$ Turcuş, Sfântul Gerard de Cenad, 33-34; cf. Györffy, « Structures ecclésiastiques », 164.

${ }^{57}$ Kristó, Histoire I, 48.
} 
évidente du respect et de la défense de la présence religieuse byzantine en Hongrie. Cette charte avait été rédigée, à ce qu'il paraît, pendant le règne d'Étienne $\mathrm{I}^{\mathrm{er58}}$.

La Legenda maior de Saint Gérard nous fournit une autre preuve éloquente du fait que Saint Étienne mettait sur le même pied d'égalité le christianisme de rite latin et celui de rite oriental, coexistant dans le Royaume magyar. Selon la Legenda maior, le duc Ajtony s'était converti vers 1002 ou 1004, à la religion chrétienne de rite oriental. Il avait fait construire une cité fortifiée, à Marosvár, y plaçant son siège ducal ainsi qu'un monastère dont le patron était « Saint Jean-Baptiste » où il avait fait venir des moines grecs et y avait installé un higoumène de Byzance ${ }^{59}$. Après la conquête du duché d'Ajtony par les Magyars et la fondation de l'évêché de rite latin de Csanád (1030), l'évêque Gérard de Csanád établit sa résidence épiscopale dans le monastère grec fondé par Ajtony; les moines grecs furent transférés au monastère "Saint Georges », fondé par Gérard de Csanád (Chanadinus) à Oroszlámos (aujourd'hui Banatska Arandjielovo en Serbie). La Legenda maior nous relate que le transfert des moines grecs de Csanád à Oroszlámos s'était fait en toute tranquillité, ce qui montre que ceux-ci avaient reconnu l'autorité hiérarchique de Saint Gérard. Donc, la Legenda maior reflète la coexistence des moines de rite latin et de ceux de rite grec dans l'espace du Royaume magyar, pendant la première moitié du $\mathrm{XI}^{\mathrm{e}}$ siècle ${ }^{60}$.

La relation spéciale entre la royauté magyare et la papauté a fait que le roi reçoive le privilège important de nommer les occupants des hautes fonctions ecclésiastiques, droit que la papauté refusait à l'empereur. Ceux qui étaient nommés dans les fonctions ecclésiastiques faisaient partie des gens de la suite du roi. Si certains prélats nommés ainsi étaient, en même temps, membres de la Cour royale (Curia regis) prouve clairement l'étroite unité entre trône et autel. D’ailleurs, selon J. Szúcs, «la première construction politique arpadienne fut basée sur les gens de la suite du prince (Gefolgschaft), suite formée de deux cercles concentriques. Le premier cercle était constitué par l'Église et l'aristocratie tribale, définie par le roi Étienne dans Libellus de Institutione morum comme « milice », non pas comme « service ». Le deuxième cercle était formé par une masse rurale hétérogène » ${ }^{61}$.

La majorité des collaborateurs ecclésiastiques du roi venait d'Allemagne. Il y a des preuves directes et indirectes qui attestent le fait que plusieurs notaires de la chancellerie impériale, les secrétaires des archevêques Heribert, Bruno et Egilbert, étaient venus de Hongrie où ils avaient déployé leur activité initiale comme notaires, pour être nommés ensuite évêques ${ }^{62}$. La Legenda maior de Saint Gérard nous fournit des informations intéressantes sur la relation entre Étienne I ${ }^{\mathrm{er}}$ et l'évêque Gérard de Csanád, ainsi que sur le soutien accordé à l’Église par le roi. En 1015, Gérard - alors, moine bénédictin au monastère San Giorgio de Venise - arriva à la cour du roi magyar. Étienne $\mathrm{I}^{\text {er }}$ convainquit Gérard de rester à la cour royale; il le chargea de s'occuper, en tant que magister, de l'éducation du prince Émeric, l'héritier du trône du Royaume magyar. En 1030, après la défaite d'Ajtony, Gérard devint évêque titulaire du diocèse de Csanád, nouvellement fondé. Jusqu'à sa mort,

\footnotetext{
${ }^{58}$ Gyula Moravcsik « The Role of the Byzantine Church in Medieval Hungary », American Slavic and East European Review, 6, (1947), 3-4, 143-144.

59 « Legenda Maior », 10, 28: « ... secundum ritum Graecorum in civitati Budin fuerat baptizatus ; ... construxit in praefata urbe Morisena monasterium in honore beati Joannis Baptistae, constituens in eodem abbatem cum monachis Graecis, juxta ordinem et ritum ipsorum ».

${ }^{60}$ Şerban Turcuş, « Monahismul ortodox în Transilvania la începutul celui de-al doilea mileniu »[《 Le monachisme orthodoxe dans Transylvanie au début du deuxième millénaire »], Tabor, 2, (2011), $79,82$.

${ }^{61}$ Apud Iogna-Prat, « Constructions chrétiennes », 62.

${ }^{62}$ Györffy, « La christianisation », 72.
} 
R. M. Feraru

en $1046^{63}$, le destin de Saint Gérard fut étroitement lié au territoire situé au sud-ouest de l'actuelle Roumanie, lequel, à partir du XVIII ${ }^{\mathrm{e}}$ siècle, est connu sous le nom de Banat.

Dès la fondation de l'évêché de Csanád, le soutien accordé à l'Église par Étienne $\mathrm{I}^{\mathrm{er}}$ fut une priorité pour sa politique religieuse ; le roi magyar se servit de l'évêché nouvellement créé pour organiser du point de vue administratif le territoire conquis. Le roi assura Gérard qu'il aurait, en peu de temps, à sa disposition le personnel - un clergé instruit - ainsi que les ressources nécessaires pour administrer l'évêché et accomplir sa mission pastorale ${ }^{64}$. C'est dans ce but qu'Étienne I ${ }^{\text {er }}$ prit la décision d'instituer la dîme ecclésiastique en céréales, dans les contrées placées sous l'autorité pastorale de Gérard ${ }^{65}$. On suppose aussi que le tiers des revenus obtenus des taxes perçues pour l'exploitation du sel était versé à l'évêché de Csanád ${ }^{66}$. De plus, il ne serait pas exclu que tous les monastères qui se trouvaient sous la juridiction de Saint Gérard fussent dispensés du paiement de la taxe sur le sel. Par analogie avec d'autres cas documentés tant en Occident que dans Byzance ${ }^{67}$, on pourrait supposer que Gérard eût bénéficié d'importants revenus obtenus par l'exploitation et la valorisation du sel ${ }^{68}$. Les donations importantes faites par Étienne $\mathrm{I}^{\mathrm{er}}$ pour construire des endroits de culte prouvent le soutien incontestable accordé à l'Église par la royauté. Selon la Legenda maior, le roi magyar contribua avec 1000 marks à l'érection du monastère Saint Georges de Csanád, dont le fondateur fut l'évêque Gérard ${ }^{69}$. Dans le même monastère, Étienne $\mathrm{I}^{\mathrm{er}}$ fit ériger un autel en l'honneur de la Vierge Marie, protectrice du Royaume magyar $^{70}$. En 1037, Saint Gérard fonda à Csanád le premier monastère bénédictin dédié à la

${ }^{63}$ «Legenda maior » 1, $22 ; 9,27:$ « Gerardus nacione Venetus, de civitate Veneciensi natus in palacio patriciae familiae $[\ldots]$.... fecitque eum filii sui Hemerici ducis magistrum diebus multis », Turcuş, Sfântul Gerard de Cenad, 57-66, 77, 82-83, 97.

${ }^{64}$ Ibid., 11, 30: «Sed quia clericos, quibus solet decorari praesul ecclesiasticus ad praesens non habemus in obsequium vestri, tollamus ecclesiarum et monasteriorum clericos et monachos, qui secundum ordinem ecclesiasticae institucionis sint nobis in divino officio adjutores [...] Tantummodo exercitate in Christi obsequio officium vestrum praedicando, baptizando, ac infideles ad Christum convertendo ».

${ }^{65}$ Ibid., 11, 30: «Ego autem comitibus meis praecipiam ut a populo tempore suo decimas exigant in bladis, quibus utaris », («Et moi, j'ordonnerai à mes comtes de prétendre à temps du peuple des dîmes en céréales, dont tu userais »).

${ }^{66}$ Geza Kovach, « Date cu privire la transportul sării pe Mureș în secolele X-XIII », [ « Données concernant le transport du sel sur Maros dans $\mathrm{X}^{\mathrm{e}}-\mathrm{XIII}^{\mathrm{e}}$ siècles »] Ziridava, XII, (1980), 193-199, apud Turcuș, Gerard de Cenad, 112, la note 24 .

${ }^{67}$ Beaucoup de monastères d'Occident et de l'Empire byzantin détenaient des salines et jouissaient des revenus obtenus par l'exploitation du sel. Ils disposaient des moyens nécessaires et de la main d'œuvre spécialisée pour l'exploitation et la commercialisation du sel. Par exemple, en Lorraine, l'évêque et les églises de Metz détenaient le droit de son extraction. Dans Byzance, le monastère "Saint Démétrius » de Thessalonique et le monastère copte de Saint Siméon de la Haute-Égypte possédaient des salines. Par un édit émis en 688/689, l'empereur Justinien II accordait à l'Église «Saint Démétrius » de Thessalonique la possession d'une saline et de ses revenus et l'exemption de toute charge ou impôt, Turcuș, Sfântul Gerard din Cenad, 112, note 25; 113-114; Georgije Ostrogorski, Histoire de l'État byzantin, traduit de l'allemand par J. Gouillard, (Paris : Payot, 1996), 161 , note 1 .

${ }^{68}$ D'après ce que relate Jean de Lyon, vers les années 1184-1185, on apprend que l'évêque de Csanád obtenait 2000 marks de la valorisation du sel, Petru Iambor, « Drumuri și vămi ale sării din Transilvania în perioada feudalismului timpuriu » Acta Musei Napocensis, 19, (1982), 76.

69 «Legenda maior » 15, 34: « Ad opus quoque sancti Georgii martiris mille marcas promisit, quas in diebus suis integraliter juxta promissum adimplevit », (« Pour les besoins du [monastère] du Saint martyr Georges, il promit mille marks et il tint sa promesse du temps de son vivant $»)$.

${ }^{70}$ Ibid., 13, 32: « ... principale quoque monasterium, quod in honore beati Georgii martiris ad litus Morosii construxit, sedem Morisenam appellavit. Beatus autem rex Stephanus ipsam nobiliter dotalibus muneribus exornavit, in quo monasterio aram ad honorem Dei Genitricis erigens et ante ipsam thuribulum argenteum fixit, duos provectae aetatis adhibens homines, in ministerio ad vigilandum, quatenus ad nullius horae spaciumibi odor thymiamatis deest ». ( «...et il nomma le plus important monastère, qu'il avait érigé sur le bord du Maros, siège marosien. Et l'heureux roi Étienne le fit orner très honorablement avec des dons; il y éleva un autel à la gloire 
Vierge Marie, monastère qu'il choisit comme lieu de sépulture. Ce monastère avait été érigé avec le soutien de la royauté, étant muni par le couple royal, de 500 marks et d'autres dons précieux pour sa décoration $^{71}$.

La Legenda maior fait seulement des allusions aux relations d'Étienne $\mathrm{I}^{\mathrm{er}}$ avec l'évêque Gérard, sans fournir des détails. Le biographe anonyme de Saint Gérard écrit que « ce que beaucoup de nobles ne pouvaient obtenir du roi, c'est seulement lui [Gérard] qui pouvait l'obtenir $»^{72}$. Mais l'évêque avait gagné en égale mesure la confiance et le respect du clergé, dont il soutenait la cause devant le roi chaque fois que cela était nécessaire ${ }^{73}$. Selon les sources que nous avons consultées, l'évêque Gérard aurait fait partie de la suite royale, à l'occasion de la visite faite à Rome par Étienne I ${ }^{\mathrm{er}}$, vers 1035 . Il parait que, lors de cette visite, l'évêque Gérard aurait obtenu l'approbation du pape pour qu'il soit enseveli dans l'église consacrée à la Vierge Marie, église qu'il avait fondée lui-même à Marosvár ${ }^{74}$.

\section{La politique religieuse des rois Pietro Orseole et Aba Sámuel}

Après la mort de son unique fils, le duc Imre (1031) - l'héritier légitime du trône du royaume magyar - Saint Étienne fut obligé de chercher un autre successeur au trône. Finalement, il désigna comme successeur, son petit-fils, Pierre Orseole, qui vivait à Venise ${ }^{75}$. Cette décision attira le mécontentement de Vazul et de Szár László (Ladislas le Chauve), les fils de l'oncle paternel d'Étienne, eux aussi prétendants au trône. Le qualificatif de szár (au crâne rasé) indique que Ladislas était païen. En échange, Vazul - dont le nom est une variante du grec Basileos - était probablement chrétien, mais de rite grec. Le fait d'avoir choisi Pierre Orseolo comme successeur au trône montre que pour le roi Étienne $\mathrm{I}^{\mathrm{er}}$, il était essentiel qu'il maintienne le christianisme de rite latin en Hongrie. En 1032, Vazul se révolta contre le roi. Il fut aveuglé par ordre d'Étienne ${ }^{\text {er }}$, qui le rendit inapte de régner. Les trois fils de Vazul, Levente, André et Béla, furent chassés de Hongrie ${ }^{76}$.

À la mort du roi Étienne $\mathrm{I}^{\text {er }}$ (1038), ce fut Pierre Orseolo qui monta sur le trône (1038-1041). En ce qui concerne la politique religieuse, le roi Pierre contribua de manière substantielle à l'expansion de l'Église. Il fonda le chapitre collégial de Buda (Óbuda) et fit ériger la cathédrale de Pécs. Autour de l'an 1040, il fonda l'évêché de Vác (Waitzen) ${ }^{77}$. D'autre part, le roi prit une série de mesures abusives

de la Théotokos et plaça devant l'autel un encensoir d'argent et choisissant deux hommes plus âgés, leur ordonna de veiller à ce que dans le monastère il n'y ait pas une heure sans l'odeur de l'encens »).

${ }^{71}$ Ibid., 15, 34: « Monasterio autem beatae Virginis, ubi sibi locum sepulturae elegerat, illa vice quingentarum marcarum summam a domino rege obtinuit, cum decem peciis purpurarum vel quinquaginta peciis pannorum, a regina vero quatour pecias purpurae ac totidem sindones »; ( « Pour le monastère de la bienheureuse Vierge, où il avait fixé le lieu de sa sépulture, il reçut alors cinq cents marks de la part de son maître, le roi, ainsi que dix morceaux de pourpre et cinquante morceaux de drap; de la part de la reine, il reçut quatre morceaux de pourpre et tout autant de morceaux de fine toile »), voir aussi Dumitru Țeicu, Geografia eclesiastică a Banatului medieval, (Cluj-Napoca: Presa Universitară Clujeană, 2007), 22.

${ }^{72}$ Ibid., 15, 34: « ... et multitudo nobilium ei veniam impetrare nullatenus potuisset, iste solus obtinuit ».

${ }^{73}$ Ibid., 15, 34: « Diebus autem quibus erat apud regem, episcopi, abates, nobiles, sacerdotes et clerici erant congregati, qui admirabantur de conversacione et sanctitate ejus Deum glorificantes », («Et pendant les jours où il se trouvait chez le roi, des évêques, des higoumènes, des nobles, des prêtres et des ecclésiastiques qui s'y trouvaient aussi, admiraient son comportement et son caractère saints, louant Dieu »).

${ }^{74}$ Turcuș, Sfântul Gerard de Cenad, 107.

${ }^{75}$ Pierre Orseole est né du mariage du doge de Venise, Otton II, avec la fille du roi Étienne ${ }^{\text {er }}$, voir Turcuş, Sfântul Gerard de Cenad, 65, 120-121.

${ }^{76}$ Kristó, Histoire I, 49-50.

${ }^{77}$ Nowak, « Das Papsttum und Ostmitteleuropa », 343-344; Kristó, Histoire I, 47; László Koszta, « State Power ", 72; Idem « La fondation de l'évêché de Vác», Specimina Nova Pars Prima. Sectio Mediaevalis I, (Pécs : Martha Font, 2001), 87-105. 


\section{R. M. Feraru

par lesquelles il se fit de nombreux ennemis, parmi les aristocrates laïques et au sein de l'Église. Il décida de destituer deux évêques et de chasser de la cour royale les aristocrates laïques d'orientation païenne, remplaçant les derniers par des étrangers, surtout des Allemands et des Italiens, qui soutenaient sans réserve le pouvoir royal. Les aristocrates magyars tombés en disgrâce et chassés de la cour dressèrent un complot contre le roi Pierre. En septembre 1041, ils élurent roi le beau-frère d'Étienne $\mathrm{I}^{\mathrm{er}}$, Aba Sámuel, qui avait détrôné Pierre ; celui-ci fut obligé de se réfugier à la cour du roi allemand, Henri III, tandis que Aba Sámuel, l'usurpateur du trône, fut excommunié par le pape ${ }^{78}$.

Le début du règne d'Aba Sámuel fut marqué par un acte de vengeance : les partisans du roi usurpateur tuèrent tous les collaborateurs de Pierre. Aba Sámuel abolit les lois et les impôts que Pierre avait institués. Pour légitimer son autorité royale, le roi usurpateur fit appel à l'évêque Gérard, sollicitant son aide pour le couronnement. Selon la Legenda maior, Aba se rendit à Csanád pour être couronné par Saint Gérard. Le roi arriva à la cathédrale épiscopale de Csanád, accompagné par une suite d'évêques qui n'avaient pas respecté la décision du pontife romain de l'excommunier. Le Dimanche de la Résurrection, les chefs tribaux et les évêques partisans d'Aba Sámuel prièrent l'évêque de Csanád de couronner le roi usurpateur. Malgré le refus de celui-là d'oindre Aba roi, les évêques qui lui étaient dévoués le couronnèrent avec une grande pompe. Dans ces conditions, Saint Gérard monta dans l'ambon et, reprochant à Aba Sámuel les atrocités qu'il avait commises, il fit la prophétie de sa chute imminente ${ }^{79}$. Cet épisode dont le déroulement réel n'a pas encore été entièrement prouvé, peut être compris plutôt dans le sens d'une réitération de l'appartenance de Gérard au courant réformiste philo-romain ${ }^{80}$. Les chroniques magyares décrivent le comportement inaccoutumé d'Aba Sámuel. Le roi est accusé d'avoir toujours méprisé les nobles, leur préférant la compagnie des paysans roturiers à côté desquels il montait à cheval et faisait la noce ; on lui reprochait aussi qu'il soutenait l'idée que les maîtres et leurs domestiques devaient jouir en commun des biens qu'ils avaient ; de plus, Aba Sámuel ne reconnaissait pas le saint sacrement de la confession, ni, en général, les saints sacrements de l'Église; il méprisait aussi le serment ${ }^{81}$. Le comportement du roi pourrait s'expliquer par le fait qu'Aba Sámuel, suivant les conseils des évêques, voulait rétablir en Hongrie les principes du christianisme primaire. Cependant, on peut aussi constater qu'il encourageait les éléments païens et hérétiques qui visaient à annihiler l'Église et l'État. Sans doute, l'évêque Gérard fait-il allusion, dans son ouvrage Deliberatio, au roi Aba Sámuel et aux difficultés auxquelles se heurtait l'Église pendant son règne. Plus précisément, Saint Gérard accusait un roi magyar, dont il ne mentionne pas le nom, de vouloir confisquer les biens de l'Église et faire les évêques payer des impôts ; il avait, en même temps, marginalisé les hiérarques de l'Église et réduit au silence les prêtres ${ }^{82}$.

Gérard plaint en même temps la situation grave de l'Église qui était affectée par « l'inouïe hérésie du siècle » dont les adeptes contestent l'autorité des évêques et du clergé, méprisant les règles et les

\footnotetext{
${ }^{78}$ Kristó, Histoire I, 51-52 ; Turcuș, Sfântul Gerard de Cenad, 121.

79 « Legenda maior »16, 35.

${ }^{80}$ Turcuș, Sfântul Gerard de Cenad, 122.

81 Szegfü László, «Eretnekség és tirannizmus »[L’Hérésie et tyrannie], Irodalomtörténeti Közlemények, (LXXII), 5, (1968), 514.

${ }^{82}$ Deliberatio IV, 51: «Non aestimes frater carissime minorem persecutionem et haeresem antiquioribus hanc esse [...] Prohibemur iam loqui, et episcopi nominamur constituti etiam sub tributo [timore humano], quibus totus committitur divino imperio mundus. Nam quorundam, nisi fallor, intentio est, quo ecclesiastica virtus suffragantibus Methodianistis atque dignitas apud nos circa haereticorum libitum tota quandoque infirmetur », ( « Ne pense pas, très cher frère, que cette persécution et cette hérésie soient moindres que celles des temps anciens... On nous défend de parler et quand nous sommes nommés évêques, nous sommes déjà obligés à payer des tributs, par peur des hommes, quoique le monde entier nous soit confié par ordre de Dieu. Si je ne me trompe, l'intention de certains est que le pouvoir ecclésiastique soit affaibli par les adeptes de Méthode et que toute notre dignité soit mise à la disposition des hérétiques »); voir aussi Deliberatio IV, 54; VII 119.
} 


\section{\begin{tabular}{l|l} 
R. M. Feraru & 51
\end{tabular} \\ L'Église et l'État en Hongrie dans la première moitié du XIe siècle, avec un regard spécial sur Legenda Sancti Gerardi et Deliberatio}

enseignements de l'Église ${ }^{83}$. L'hérésie à laquelle fait allusion l'évêque Gérard est le bogomilisme, apparu en Bulgarie au début du $\mathrm{X}^{\mathrm{e}}$ siècle. De la Péninsule Balkanique, l'hérésie bogomile s'est répandue en Hongrie ${ }^{84}$; elle fut embrassée, paraît-il, par le roi Aba Sámuel lui-même. Les chroniques magyares nous laissent entendre que le comportement du roi et ses principes coïncidaient avec les enseignements du bogomilisme. Cette hérésie avait aussi de nombreux adeptes dans la suite du roi ${ }^{85}$.

Le gouvernement despotique d'Aba Sámuel diminua le nombre de ceux qui le soutenaient, dont les intérêts avaient été considérablement lésés. Les opposants du roi s'adresseront à l'empereur Henri III, lui demandant de faire cesser les actes de violence du roi magyar. Après avoir reçu l'autorisation du pontife romain, Henri III infligea une terrible défaite à Aba Sámuel dans la bataille de Ménfö (près de Györ), le 5 juillet 1044. Avec le soutien du souverain allemand, Pierre Orseolo devint pour la seconde fois roi de Hongrie (1044-1046). Il prêta le serment de fidélité envers le souverain allemand, tout en acceptant l'établissement des troupes militaires allemandes sur le territoire de la Hongrie ${ }^{86}$.

En 1046, la Hongrie fut enflammée par la révolte des Magyars contre Pierre Orseolo, qui avait mis les possessions du royaume à la disposition des Allemands et des Italiens. Après avoir détrôné Pierre Orseolo, ses opposants firent venir de Pologne, avec l'assentiment de Saint Gérard, les princes arpadiens André et Levente (les fils de Vazul), auxquels on proposa le trône de Hongrie. L'évêque Gérard fut directement impliqué dans le détrônement de Pierre Orseolo. D'ailleurs, on le sait: la conspiration contre le roi fut déclenchée à Csanád, ce qui implique que l'évêque se trouvait sûrement à la tête des conspirateurs ${ }^{87}$.

À la fin de l'été de l'an 1046, les dirigeants des tribus magyares se réunirent dans l'Albe Royale, d'où Saint Gérard, accompagné par trois évêques (Bistriza, Böd et Beneta) partirent pour Buda pour accueillir les deux princes arpadiens, André et Levente. Ce fut en même temps qu'éclata en Hongrie la révolte des Magyars païens ayant à leur tête Vata, qui demandaient que le pays revienne à " l'époque d'or » des nomades magyars, et donc, ils demandaient aussi la persécution du clergé chrétien, coupable de l'abandon des traditions ancestrales. Gérard lui-même tomba victime de cette révolte, étant tué à Pest par les partisans de Vata (le 24 septembre 1046) ${ }^{88}$. Les fils de Vazul, André et Levente, reçurent une aide importante de la part des masses païennes dans la lutte contre l'ancien roi Pierre Orseolo ; les partisans de Vata s'adonnèrent à des massacres abominables contre les membres du clergé et détruisirent de nombreuses Églises chrétiennes. Après la défaite de Pierre Orseolo, André

\footnotetext{
${ }^{83}$ Deliberatio IV, 50-51: « Pro dolor, vero nunc multi pullulant in ecclesia, immo iam totum occupant orbem, et nemo est, qui talium ineptiis contradicat. $\mathrm{O}$ quantos sentio diaboli filios, quibus loqui non patior. [...] Hoc tempore omnes maledixerunt apud nos concitati zelo non solum divinis ritibus et ecclesiae et sacerdotibus, quin etiam ipsi Dei Filio Iesu Christo Domino nostro. Omnibus inaudita saeculi haereses [sic!] repetere elemosinas pro animabus defunctorum Christianorum more expensas ... Omnes uno paene simul ore carnis negant resurrectionem, qua iniquitate nulla umquam in mundo maior iniquitas arbitranda », (« Mais hélas! Beaucoup d'hérétiques pullulent maintenant dans l'Église et il n'y a personne pour combattre leurs inepties. Ô combien, je les connais, sont les fils du diable, dont je ne supporte même pas de parler ! Pendant ce temps-là, tous ont proféré des blasphèmes, s'enflammant non seulement contre les règles ecclésiastiques, de l'Église et des prêtres, mais même contre le Fils de Dieu, Jésus Christ, notre Seigneur. L'hérésie inouïe de notre temps est que tous, ils refusent la coutume de faire, par pitié, des dons pour les âmes des chrétiens défunts...Tous, presque d'une seule voix, nient la Résurrection, or, il n’y a au monde plus grand blasphème que cette iniquité »).

${ }^{84}$ Saint Gérard fait deux fois une vague allusion à l'extension des hérésies en Hongrie; il se rapporte explicitement aux péchés et à la simonie qui se sont répandus en Pannonie, Deliberatio III, 37; V, 70; vezi şi László, "Eretnekség és tirannizmus », 509-510 ; pour l'apparition et l'extension du bogomilisme, voir Ostrogorski, Histoire de l'État, 295-296.

${ }^{85}$ László, « Eretnekség és tirannizmus », 514-515; Kristó, Histoire I, 52.

${ }^{86}$ Kristó, Histoire I, 52-53.

${ }^{87}$ Kristó, Histoire I, 53.

${ }^{88}$ « Legenda maior », 17-18, 35-37.
} 


\section{R. M. Feraru 52 \\ L'Église et l'État en Hongrie dans la première moitié du XIe siècle, avec un regard spécial sur Legenda Sancti Gerardi et Deliberatio}

monta sur le trône de la Hongrie (1046). Il chassa les païens et se consacra à l'organisation interne du royaume magyar. Le nouveau roi ordonna au peuple d'abandonner les traditions païennes et de vivre selon la loi d'Étienne $\mathrm{I}^{\mathrm{er}}$.

\section{Conclusions}

Le couronnement d'Étienne $\mathrm{I}^{\mathrm{er}}$ comme roi de Hongrie (1001) a constitué un moment décisif dans le procès de transformation du gouvernement magyar en Pannonie : d'une simple union de tribus, celuici est devenu État chrétien, solidement articulé. Depuis le règne d'Étienne I ${ }^{\text {er }}$, l'étroite relation entre l'Église et la royauté magyare a caractérisé l'organisation politique de la Hongrie médiévale. D'ailleurs, dans la vision du premier roi magyar, la fondation d'un État chrétien se trouvait en étroite liaison avec l'organisation de l'Église. Le roi Étienne I $^{\text {er }}$ se servit de l'Église comme d'un instrument nécessaire à l'accomplissement de ses projets politiques. L'acte de christianisation des Magyars a eu un caractère politique, reliant définitivement la Hongrie à l'Occident de l'Europe. L'ascendant de l'Empire romain-germanique sur les Magyars ainsi que les étroites relations entre la royauté magyare et les ducs de Bavière ont eu comme principale conséquence leur christianisation selon le rite occidental. La reconnaissance papale du titre de roi et le couronnement de Vajk-Étienne avec l'accord du pape ont établi entre la royauté magyare et le Saint Siège une relation de dépendance spirituelle, ce qui explique le caractère apostolique de propagateur de la nouvelle foi, associé, dès le début, au jeune État magyar.

L'organisation de l'Église magyare fut presque entièrement l'œuvre d'Étienne $\mathrm{I}^{\mathrm{er}}$. Ce processus présente une certaine parenté avec le modèle ecclésiastique allemand de l'époque. À la différence de l'Église impériale d'Allemagne, l'Église magyare n'a pas joué un rôle tout aussi important dans le fonctionnement de l'État. Le souverain magyar avait à sa disposition et sous son commandement direct le système de comitats (comtés) qui, dans le domaine de l'administration, de la juridiction et de l'organisation militaire représentait les intérêts du pouvoir royal central. Il n'était pas obligé de se baser sur le soutien de l'Église comme c'était le cas des monarques allemands.

L'évêque Gérard de Csanád a joué un rôle fondamental dans l'implantation des structures administratives magyares sur le territoire de son diocèse. Le couple Gérard - Étienne le Saint représente un modèle significatif d'équilibre et de collaboration entre sacerdotium et regnum. Gérard apparaît ainsi comme un représentant du courant réformateur, qui avait commencé dans le milieu monastique, en culminant avec Grégoire VII, le pontife qui allait introduire l'évêque de Marosvár parmi les saints, en 1083. Sans l'affirmer nettement, Saint Gérard partageait l'idée que les pouvoirs temporel et spirituel avaient la même dignité et la même justification, bien que dans sa vision, le second fût supérieur au premier, puisque c'était Dieu qui avait confié aux ecclésiastiques le monde entier.

À certains moments, l'Église, par les pouvoirs civil et politique accordés à ses évêques, s'était substituée aux autorités civiles de l'État. Ainsi, dans les conditions de la crise déclenchée à la fin du premier règne de Pierre Orseolo (1041), l'Église s'est manifestée comme un facteur de décision sur la scène de la vie politico-religieuse du royaume magyar. En 1046, l'Église, grâce à l'évêque Gérard, a eu une contribution décisive dans l'effort de sauvegarder de la dissolution l'État magyar par la répression de la révolte païenne de Vata et l'avènement au trône du prince André.

La convergence entre l'Église et la royauté magyare d'une part, et la relation directe avec Rome, d'autre part, a eu deux conséquences importantes : la Hongrie n'a pas été affectée par les mouvements politiques par lesquels ont dû passer les autres États monarchiques européens, dans le contexte du 
conflit entre la papauté et l'Empire romain-germanique des $\mathrm{X}^{\mathrm{e}}-\mathrm{XIII} \mathrm{I}^{\mathrm{e}}$ siècles. Dans sa qualité d' « avant-poste » du catholicisme en Europe centrale et de sud-est, la royauté magyare a toujours été loyale à la papauté, dont elle a eu besoin de manière permanente. D'autre part, le droit des rois de nommer des ecclésiastiques dans les fonctions hiérarchiques de l'Église a créé une sorte d'étatisme précoce dans les rapports de la royauté avec le clergé magyar ; cet étatisme ne fut rencontré nulle part en Europe à cette époque-là. La fidélité des rois magyars envers Rome a été doublée par la loyauté de l'Église de Hongrie envers sa propre royauté.

\section{Bibliographie selective}

\section{Sources primaires}

A Szent István, Szent László és Kálmán korabeli törvények és zsinati határozatok forrásai (De fontibus legum et decretorum synodalium e temporibus sancti Stephani, sancti Ladislai et Colomani oriundorum), édité par Levente Zárodszky. Budapest: 1904.

Chronik des Bischofs Thietmar von Merseburg und ihre Korveier Überarbeitung, édité par Robert Holtzmann (Monumenta Germaniae Historica Scriptores. Nova Series). Berlin: Weidmann, 1935.

Gérard de Csanád, Deliberatio Gerardi Moresenae Ecclesiae Episcopi supra Hymnum Trium Puerorum ad Isingrinum Liberalem édité par Gabriel Silagi (« Corpus Christianorum: Continuatio Mediaevalis » 49). Turnhout: Brepols, 1978.

"Legenda maior. Vita Sancti Gerardi, Moresanae ecclesiae episcope" in Documente privitoare la istoria Mitropoliei Banatului, [Documents concernant l'histoire d'archêveché du Banat] édité par Ioan D. Suciu, Radu Constantinescu, 22-63. Timișoara: Mitropolia Banatului, 1980.

"Legenda Sancti Stephani regis ab Hartvico episcopo conscripta" II, in Scriptores rerum Hungaricarum tempore ducum regumque stirpis Arpadianae gestarum, édité par E. Szentpétery, Budapest: 1938.

Scriptores rerum germanicarum: Liudprandi opera, herausgegeben von Joseph Becker, Hannover und Leipzig: Hahnsche Buchhandlung, 1915.

\section{Ouvrages, études et articles}

Gerard din Cenad: Armonia lumii sau Tălmăcire a cântării celor trei coconi către Insingrim dascălul, [Gérard de Csanád: L'Harmonie du monde ou interprétation du chant des trois garçons dedié à Isingrim le maître], étude introductive, sélection, traduction et commentaires par Radu Constantinescu, avant-propos par Răzvan Theodorescu. București: Meridiane, 1984.

Fuhrmann, Horst. "Provincia constat duodecim episcopatibus." Studia Gratiana, XI, (1967): 389-404.

Györffy, György. "Structures ecclésiastiques de la Hongrie médiévale." Miscellanea historiae ecclesiasticae V, (Colloque de Varsovie, octobre 1971), (1974): 159-167.

. "La christianisation de la Hongrie." Harvard Ukrainian Studies XII-XIII, 1988/1989 (Proceedings of the International Congress Commemorating the Millenium of Christianity in Rus'Ukraine), édité par Omeljan Pritsak et Ihor Ševčenko, (1990): 61-74.

Iogna-Prat, Dominique. "Constructions chrétiennes d'un espace politique." Le Moyen Age. Revue d'histoire et de Philosophie, 1, (2001): 49-69.

Klaniczay, Gábor. "Rex iustus. Le saint fondateur de la royauté chrétienne." Cahiers d'Études hongroises, 8, (1996) : 34-58. 


\section{\begin{tabular}{l|l} 
R. M. Feraru 54
\end{tabular} \\ L'Église et l'État en Hongrie dans la première moitié du XIe siècle, avec un regard spécial sur Legenda Sancti Gerardi et Deliberatio}

Kristó, Gyula. Histoire de la Hongrie médiévale, Tome I: Le temps des Árpáds, préface de Sándor Scernus et Noël-Yves Tonnerre, traduit du hongrois par Chantal Philippe. Rennes: Presses Universitaires de Rennes, 2000.

Koszta, László. "State Power and Ecclesiastical System in Eleventh Century Hungary. (An Outline to the Dynamics of the Development of Hungarian Christian Church)." "In my spirit and thougth I remained a European of Hungarian origin". Medieval Historical Studies in Memory of Zoltan J. Kosztolnyik, édité par István Petrovics, Sándor László Tóth, Eleanor A. Congdon, 67-78. Szeged: JatePress, 2010.

László, Szegfü. "Eretnekség és tirannizmus" [L’Hérésie et tyrannie]. Irodalomtörténeti Közlemények, (LXXII), 5, (1968), 501-516.

Nowak, Przemysław. "Das Papsttum und Ostmitteleuropa (Böhmen - Mähren, Polen, Ungarn, vom ausgehenden 10. bis zum Beginn des 13. Jahrhunderts) mie einer Neuedition von JL 9067." Rom und Die Regionen. Studien zur Homogenisierung der lateinischen Kirche im Hochmittelalter, Band 19, Herausgegeben von Jochen Johrendt und Harald Müller, 331-370. Berlin/Boston: Walter de Gruyter, 2012.

Platon, Alexandru-Florin et Laurențiu Rădvan, Bogdan-Petru Maleon. O istorie a Europei de Apus în Evul Mediu. De la Imperiul Roman târziu la marile descoperiri geografice (secolele V-XVI), [Une histoire de l'Europe de l'Ouest dans le Moyen Âge. De l'Empire romain tardif aux grandes découvertes géographiques ( $V^{e}-X V I^{e}$ siècles)]. Iași: Polirom, 2010.

Sághy, Marianne. "L’organisation des Églises en Hongrie autour de l'An Mil: Le cas de l'évêché de Csanád." Archivum Bobiense - Studia IV: Gerberto d'Aurillac da abate di Bobbio a papa dell'anno 1000, (Atti del Congresso internationale, Bobbio, 28-30 settembre 2000) édité par Flavio G. Nuvolone, 469-481. Bobbio: Associazione culturale Bobbio / Pc; Amici di Archivum Bobiense, 2001.

Török, József. “Il primo re d'Ungheria e 1'organizzazione della Chiesa ungherese.” Archivum Bobiense - Studia IV: Gerberto d'Aurillac da abate di Bobbio a papa dell'anno 1000, (Atti del Congresso internationale, Bobbio, 28-30 settembre 2000) édité par Flavio G. Nuvolone, 455-466. Bobbio: Associazione culturale Bobbio / Pc; Amici di Archivum Bobiense, 2001.

Turcuş, Șerban. "Monahismul ortodox în Transilvania la începutul celui de-al doilea mileniu" [Le monachisme orthodoxe dans Transylvanie au début du deuxième millénaire]. Tabor, 2, (2011): 7890.

Sfântul Gerard de Cenad sau despre destinul unui venețian în jurul anului 1000 [Saint Gérard de Csanád ou sur la destin d'un vénetien vers l'an 1000]. București: Carom, 2004. 